\title{
Support Vector Regression Model of Chlorophyll-a during Spring Algal Bloom in Xiangxi Bay of Three Gorges Reservoir, China
}

\author{
Hua-Jun Luo ${ }^{1}$, De-Fu Liü, Ying-Ping Huang ${ }^{3}$ \\ ${ }^{1}$ College of Chemistry \& Life Science, Three Gorges University, Yichang, China; ${ }^{2}$ College of Hydroelectric \& Environment, Three \\ Gorges University, Yichang, China; ${ }^{3}$ Engineering Research Center of Eco-Environment in Three Gorges Reservoir Region, Ministry \\ of Education, Three Gorges University, Yichang, China. \\ Email: luohuajun@21cn.com
}

Received March $4^{\text {th }}, 2012$; revised April $6^{\text {th }}, 2012$; accepted May $5^{\text {th }}, 2012$

\begin{abstract}
To study the relationship between chlorophyll- $a$ and environmental variables during spring algal bloom in Xiangxi Bay of Three Gorges Reservoir, the support vector regression (SVR) model was established. In surveys, 11 stations have been investigated and 264 samples were collected weekly from March 4 to May 13 in 2007 and February 16 to May 10 in 2008. The parameters in SVR model were optimized by leave one out cross validation. The squared correlation coefficient $R^{2}$ and the cross validated squared correlation coefficient $Q^{2}$ of the optimal SVR model are 0.8202 and 0.7301, respectively. Compared with stepwise multiple linear regression and back propagation artificial neural network models using external validation, the SVR model has been shown to perform well for regression with the predictive squared correlation coefficient $R_{\text {pred }}^{2}$ value of 0.7842 for the test set.
\end{abstract}

Keywords: Support Vector Regression; Chlorophyll- $a$; Algal Bloom; Three Gorges Reservoir

\section{Introduction}

The eutrophication of reservoirs and lakes has been a major water quality problem for decades, causing turbid water with high algal biomass [1-3]. This trend is expected to increase by high levels of nutrient input as a result of human activities such as sewage and storm overflows, runoff of commercial fertilizer, and so on [4]. In water research and management, chlorophyll- $a$ is the fundamental index of phytoplankton abundance and a good indicator of algal bloom (a rapid increase in the biomass of phytoplankton) [5-7]. The concentration of chlorophyll- $a$ in aquatic system depends on a number of variables including nutrients, light, temperature, physicochemical properties of the water mass [8] as well as interactions between these physical, chemical and biological compartments of the system. There are many study methods to the relationship between chlorophyll- $a$ and environmental factors such as stepwise multiple linear regression (MLR) analysis [9-12] and artificial neural network (ANN) $[13,14]$. But the algal bloom is the multivariate interaction and nonlinear process. Many times, linear based methods such as MLR are not able to represent satisfactorily the correlation between chlorophyll- $a$ and respective environmental variables, because these methods do not account for non-linearity. ANN can in principle model nonlinear relations but often difficult to train or even yield unstable models and another drawback is the fact that ANN does not lead to one global or unique solution due to differences in their initial weight set.

Support vector regression (SVR), originally proposed and developed by Vladimir Vapnikn $[15,16]$, is a nonlinear machine learning technique and has many theoretical advantages in the field of chemometrics. These advantages stem from the specific formulation of a (convex) objective function with constraints which is solved using Lagrange Multipliers and has the characteristics that: 1) a global optimal solution exists which will be found, 2) the result is a general solution avoiding overtraining, 3) the solution is sparse and only a limited set of training points contribute to this solution, and 4) nonlinear solutions can be calculated efficiently due to the usage of inner products [17]. So the aim of this present paper is to construct the relationship model between chlorophyll- $a$ and environmental factors during spring algal bloom in Xiangxi Bay of Three Gorges Reservoir using support 
vector regression method.

\section{Materials and Methods}

\subsection{Area Description}

The Three-Gorge Dam (TGD) in China is the world's largest dam, measuring $2335 \mathrm{~m}$ long and $185 \mathrm{~m}$ high, and the reservoir created by it has an area of $1080 \mathrm{~km}^{2}$ in 2009 [18]. The Xiangxi River, which lies 38 km upstream from the Dam, is the largest tributary in the Hubei portion of Three-Gorge Reservoir (TGR). This river is 94 $\mathrm{km}$ long with a watershed of $3099 \mathrm{~km}^{2}$ (between $110^{\circ} 25^{\prime}$ and $111^{\circ} 06^{\prime} \mathrm{E}$ long., $30^{\circ} 57^{\prime}$ and $31^{\circ} 34^{\prime} \mathrm{N}$ lat.) [19]. With impoundment of TGR, the downriver stretch of Xiangxi River was inundated and Xiangxi Bay was formed. Then the water flow velocity has dropped from the original $0.43-0.92 \mathrm{~m} / \mathrm{s}$ [20] to $0.0020-0.0041 \mathrm{~m} / \mathrm{s}$ [21]. So when water temperature increased in spring, there were algal blooms with prolonged retention time and high nutrient concentrations in Xiangxi Bay.

\subsection{Sampling and Analysis}

Water samples were collected at 11 stations (X0 - X10) in Xiangxi River (Figure 1). Samplings were performed weekly from March 4 to May 13, 2007 and February 16 to May 10, 2008. Water samples were collected at $0.5 \mathrm{~m}$ depth from surface in the middle of the river using a $5-\mathrm{L}$ Niskin sampler (Hydrobios-Kiel). Water temperature (WT), dissolved oxygen (DO), $\mathrm{pH}$, turbidity (Turb) were recorded in situ using multi-parameter water quality analyzer (Hydrolab DS5). Total phosphates (TP), phosphate $\left(\mathrm{PO}_{4}\right)$, total nitrogen $(\mathrm{TN})$, ammonium nitrogen $\left(\mathrm{NH}_{4}\right)$, nitrate $\left(\mathrm{NO}_{3}\right)$, silicate $\left(\mathrm{SiO}_{4}\right)$ were determined in the laboratory using State Environmental Protection Administration (SEPA) standard methods [22]. For chlorophyll- $a$ (Chl- $a$ ) analysis, samples filtered through Whatman GF/F filters were extracted with cold $90 \%$ acetone and estimated by spectrophotometer [23].

\subsection{Support Vector Regression}

In support vector regression, the basic idea is to map the data $X$ into a higher dimensional feature space $F$ via a nonlinear mapping $\Phi$ and then to do linear regression in this space $[16,17]$. Therefore, regression approximation addresses the problem of estimating a function based on a given data set $G=\left\{\left(\boldsymbol{x}_{i}, d_{i}\right)\right\}_{i=1}^{l} \quad\left(\boldsymbol{x}_{i}\right.$ is input vector, $d_{i}$ is the desired value). SVR approximates the function in the following form:

$$
y=\sum_{i=1}^{l} w_{i} \Phi_{i}(x)+b
$$

where $\left\{\Phi_{i}(x)\right\}_{i=1}^{l}$ is the set of mappings of input features,

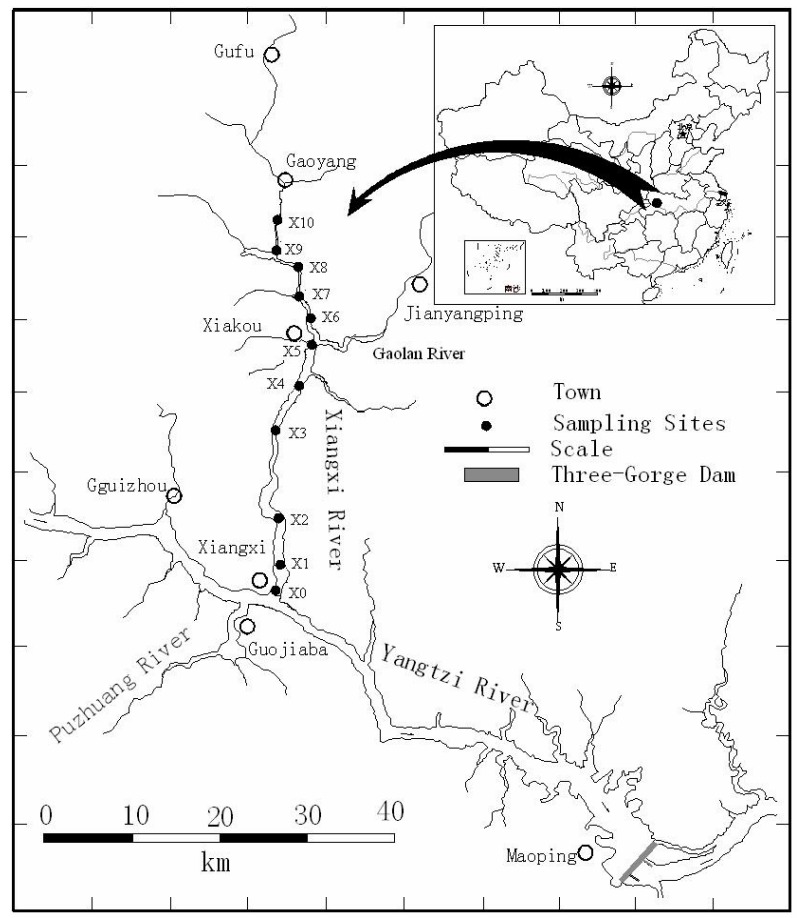

Figure 1. Sampling stations in Xiangxi Bay.

$\left\{\left(w_{i}\right)\right\}_{i=1}^{l}$ and $b$ are coefficients. They are estimated by minimizing the regularized risk function $R(C)$ :

$$
R(C)=C \frac{1}{N} \sum_{i=1}^{l} L_{\varepsilon}\left(d_{i}, y_{i}\right)+\frac{1}{2}\|w\|^{2}
$$

where

$$
L_{\varepsilon}(d, y)=\left\{\begin{array}{cc}
|d-y|-\varepsilon & \text { for }|d-y| \geq \varepsilon \\
0 & \text { otherwise }
\end{array}\right\}
$$

and $\varepsilon$ is a prescribed parameter in the insensitive loss function.

In Equation (2), $\left[C(1 / N) \sum L_{\varepsilon}\left(d_{i}, y_{i}\right)\right]$ is the socalled empirical error (risk) measured by $\varepsilon$-insensitive loss function $L_{\varepsilon}(d, y)$, which indicates that it does not penalize errors below $\varepsilon$. The second term, $\left[(1 / 2)\|w\|^{2}\right]$, is used as a measurement of function flatness. $C$ is a regularized constant determining the tradeoff between the training error and the model flatness. Introduction of slack variables $\xi$ leads Equation (4) to the following constrained function Max:

$$
\max R\left(w, \xi^{*}\right)=\frac{1}{2}\|w\|^{2}+C^{*} \sum_{i=1}^{l}\left(\xi_{i}+\xi_{i}^{*}\right)
$$

s.t. $w \Phi\left(x_{i}\right)+b-d_{i} \leq \varepsilon+\xi_{i}, \quad d_{i}-w \Phi\left(x_{i}\right)-b_{i} \leq \varepsilon+\xi_{i}^{*}$, $\xi_{i}, \xi_{i}^{*} \geq 0$.

The minimization of Equation (1) is a standard prob- 
lem in optimization theory and it can be derived that the weight vector $\boldsymbol{w}$ equals the linear combination of the training data:

$$
\boldsymbol{w}=\sum_{i=1}^{l}\left(\alpha_{i}-\alpha_{i}^{*}\right) x_{i}
$$

In this formula, $\alpha_{i}$ and $\alpha_{i}^{*}$ are Lagrange multipliers. Thus, decision function becomes the following form:

$$
f(x)=\sum_{i=1}^{l}\left(\alpha_{i}-\alpha_{i}^{*}\right) K\left(\boldsymbol{x}_{i}, x\right)+b
$$

where $K\left(x_{i}, x\right)$ is the kernel function and the value is equal to the inner product of two vectors $\boldsymbol{x}_{i}$ and $\boldsymbol{x}_{j}$ in the feature space $\Phi(x)$. That is,

$K\left(\boldsymbol{x}_{i}, x_{j}\right)=\Phi\left(\boldsymbol{x}_{i}\right) \Phi\left(x_{j}\right)$. The most used kernel functions include radial basis function (RBF) kernel, polynomial kernel and linear kernel. For the SVR calculations, a Matlab toolbox was used, developed by Gunn [24].

\section{Results and Discussion}

\subsection{Selection of the Environmental Factors}

Statistic summary of chlorophyll- $a$ and environmental factors during the observation period in Xiangxi Bay of Three Gorges Reservoir are presented in Tables $\mathbf{1}$ and $\mathbf{2}$. There is a clear spatial and temporal variation in chlorophyll- $a$ across Xiangxi Bay. The concentration of chlorophyll- $a$ ranged from 0.1280 to $160.2060 \mathrm{mg} / \mathrm{m}^{3}$ in the spring of 2007 and from 1.9380 to $335.7360 \mathrm{mg} / \mathrm{m}^{3}$ in the spring of 2008 with mean values of $11.4910 \mathrm{mg} / \mathrm{m}^{3}$ and $31.8219 \mathrm{mg} / \mathrm{m}^{3}$, respectively. Mean concentration of chlorophyll- $a$ for each station ranged from 3.6723 to $23.7129 \mathrm{mg} / \mathrm{m}^{3}$ in the spring of 2007 and from 17.5191 to $63.6717 \mathrm{mg} / \mathrm{m}^{3}$ in the spring of 2008 . The spring algal bloom in 2008 is serious than that in 2007.

The environmental variables were selected using stepwise multiple linear regression method. In the stepwise MLR method, all variables were assessed and evaluated to determine important factors. As the stepping process was terminated, the model with seven important environmental factors was obtained as follows:

$$
\begin{aligned}
\text { Chl }-a= & 157.4835+3.5579 \mathrm{DO} \\
& +18.8673 \mathrm{pH}+0.2443 \mathrm{Turb} \\
& -80.1043 \mathrm{PO}_{4}+39.8839 \mathrm{NH}_{4} \\
& -11.3617 \mathrm{NO}_{3}-4.0525 \mathrm{SiO}_{4}
\end{aligned}
$$

$\left(R^{2}=0.4131, R_{a d j}^{2}=0.3970, S=30.6541, F=25.7431\right.$, $Q^{2}=0.3526, P=0.0001, n=264$ )

The statistical quality of the regression equation was examined using parameters such as the squared correlation coefficient $\left(R^{2}\right)$, the squared adjusted correlation coefficient $\left(R_{a d j}^{2}\right)$, the standard error $(S)$, the Fisher ratio at the $95 \%$ confidence level $(F)$, and the cross validated squared correlation coefficient obtained based on Leave One Out (LOO) method $\left(Q^{2}\right)$. The stepwise MLR analysis shows that the environmental variables $(\mathrm{DO}, \mathrm{pH}$, Turb, $\mathrm{PO}_{4}, \mathrm{NH}_{4}, \mathrm{NO}_{3}, \mathrm{SiO}_{4}$ ) are more important to the

\begin{tabular}{|c|c|c|c|c|c|c|c|c|}
\hline & \multicolumn{4}{|c|}{2007} & & \multicolumn{3}{|c|}{2008} \\
\hline & Mean & Std. & Minimum & Maximum & Mean & Std. & Minimum & Maximum \\
\hline $\mathrm{X} 0$ & 3.6723 & 4.0436 & 0.4380 & 12.5890 & 23.3225 & 25.9015 & 2.0130 & 87.4200 \\
\hline $\mathrm{X} 1$ & 23.7129 & 38.9107 & 1.0150 & 132.3120 & 27.0729 & 31.6546 & 1.9380 & 92.4000 \\
\hline $\mathrm{X} 2$ & 21.5977 & 46.4572 & 0.6750 & 160.2060 & 28.6073 & 36.6705 & 2.1450 & 104.7980 \\
\hline $\mathrm{X} 3$ & 16.2165 & 29.6656 & 0.3670 & 98.7500 & 32.3891 & 64.4767 & 2.0160 & 240.5200 \\
\hline $\mathrm{X} 4$ & 5.6552 & 9.7656 & 0.1280 & 32.9670 & 17.5191 & 15.8523 & 3.6720 & 58.1500 \\
\hline $\mathrm{X} 5$ & 9.9516 & 24.1192 & 0.6100 & 82.2310 & 18.6323 & 14.0088 & 4.2240 & 43.0580 \\
\hline $\mathrm{X} 7$ & 5.3327 & 5.8171 & 0.1630 & 17.1290 & 26.1929 & 35.8963 & 4.1150 & 142.1160 \\
\hline $\mathrm{X} 8$ & 10.7885 & 12.8801 & 0.3330 & 38.4300 & 40.7369 & 61.4108 & 6.3610 & 235.8210 \\
\hline X9 & 9.0060 & 10.2170 & 0.1670 & 33.9000 & 63.6717 & 85.9708 & 5.9240 & 335.7360 \\
\hline $\mathrm{X} 10$ & 8.6895 & 13.7744 & 1.1330 & 43.6580 & 47.8277 & 59.8171 & 5.2400 & 208.8600 \\
\hline
\end{tabular}
chlorophyll- $a$ concentration of spring algal bloom in Xiangxi Bay. But Equation (7) only predicted $35.26 \%$ of the variance and explained $39.70 \%$ of the variance of chlorophyll- $a$. So the MLR model is not satisfactory.

Table 1. Statistic summary of chlorophyll- $a\left(\mathrm{mg} / \mathrm{m}^{3}\right)$ during the observation period in Xiangxi Bay. 
Table 2. Statistic summary of environmental factors during the observation period in Xiangxi Bay.

\begin{tabular}{ccccccccc}
\hline & \multicolumn{3}{c}{2007} & \multicolumn{3}{c}{2008} \\
\cline { 2 - 9 } & Mean & Std. & Minimum & Maximum & Mean & Std. & Minimum & Maximum \\
\hline $\mathrm{WT}\left({ }^{\circ} \mathrm{C}\right)$ & 16.0786 & 3.0021 & 11.1390 & 21.0700 & 14.6379 & 3.8563 & 9.3430 & 23.4960 \\
$\mathrm{DO}(\mathrm{mg} / \mathrm{L})$ & 11.0207 & 3.6202 & 1.5860 & 21.4950 & 8.6148 & 2.3404 & 4.7190 & 19.5430 \\
$\mathrm{PH}$ & 8.2857 & 0.5235 & 6.7360 & 9.1780 & 8.7269 & 0.5044 & 7.7860 & 9.9110 \\
$\mathrm{Turb}(\mathrm{NTU})$ & 8.2411 & 12.5880 & 0.2000 & 89.5500 & 13.8815 & 27.3549 & 2.6140 & 210.1430 \\
$\mathrm{TP}(\mathrm{mg} / \mathrm{L})$ & 0.1838 & 0.1020 & 0.0290 & 0.5100 & 0.7507 & 1.5386 & 0.0133 & 6.9316 \\
$\mathrm{PO}_{4}(\mathrm{mg} / \mathrm{L})$ & 0.1450 & 0.0939 & 0.0020 & 0.4200 & 0.1324 & 0.0949 & 0.0064 & 0.6639 \\
$\mathrm{TN}_{(\mathrm{mg} / \mathrm{L})}$ & 1.1259 & 0.4022 & 0.3170 & 2.4670 & 1.7713 & 0.9359 & 0.1791 & 6.3797 \\
$\mathrm{NH}_{4}(\mathrm{mg} / \mathrm{L})$ & 0.3368 & 0.1639 & 0.0600 & 0.8980 & 0.5327 & 0.2665 & 0.0042 & 2.0908 \\
$\mathrm{NO}_{3}(\mathrm{mg} / \mathrm{L})$ & 0.7392 & 0.3839 & 0.0410 & 1.5130 & 0.7382 & 0.5547 & 0.0050 & 3.0321 \\
$\mathrm{SiO}_{4}(\mathrm{mg} / \mathrm{L})$ & 3.6650 & 1.0079 & 0.9190 & 5.8810 & 4.3640 & 3.3591 & 0.0590 & 21.8886 \\
\hline
\end{tabular}

\subsection{Selection of the SVR Model Parameters}

The resulting environmental factors in Equation (7) decided by stepwise MLR were used for SVR model. The performance of SVR model is related to variables as well as the combination of parameters used in the model. So some parameters in SVR (the type of kernel function, the regularization parameter $C$ and $\varepsilon$-insensitive loss function) ought to be optimized. In this work, $Q^{2}$ was used as a measurement of generalization in leave one out cross validation (LOOCV) of SVR. Figures 2-4 illustrated $Q^{2}$ versus $\varepsilon$ and $C$ with different kernel functions [RBF with a width of $\sigma=0.10$, polynomial, linear] respectively. It is found that optimal SVR model with $Q^{2}=$ 0.7301 is available when the kernel function is polynomial with $\varepsilon=0.03$ and $C=150$. Figure 5 shows the calculated values of optimal SVR model versus observed values for chlorophyll- $a\left(R^{2}=0.8202\right)$. It can be concluded that the predicted results are in good agreement with the observation ones.

The optimal SVR model was compared with stepwise MLR and back propagation artificial neural network (BPANN). The parameters of BPANN model with three layers used were as follows: the number of hidden nodes was seven; the transformation function was sigmoid; the learning rate and momentum of each epoch were set to 0.30 and 0.20 respectively. External validation was used to compare the predictive capacity of models. The data set was randomly classified into training set ( $80 \%$ data) and test set $\left(20 \%\right.$ data) and the predictive $R^{2}\left(R_{\text {pred }}^{2}\right)$ values were calculated according to the following equation:

$$
R_{\text {pred }}^{2}=1-\frac{\sum\left(Y_{\text {pred }(\text { Test })}-Y_{\text {(Test) }}\right)^{2}}{\sum\left(Y_{\text {(Test) }}-\bar{Y}_{\text {training }}\right)^{2}}
$$

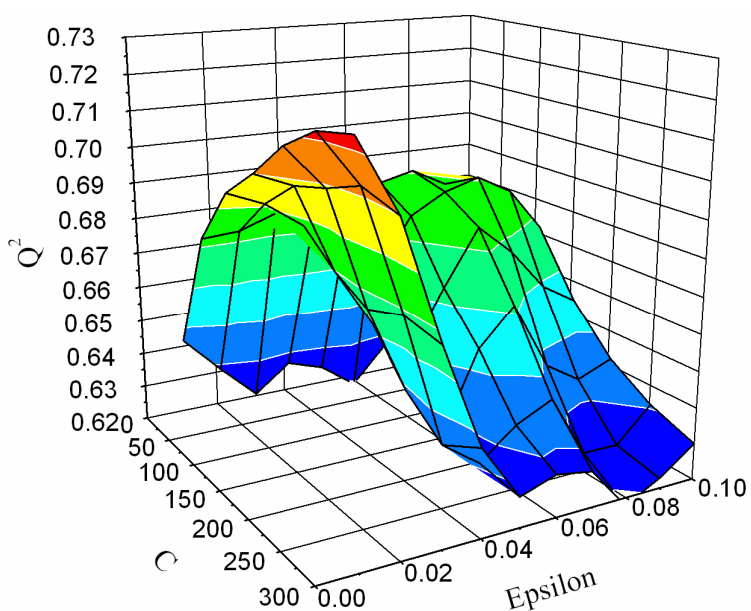

Figure 2. $Q^{2}$ versus $\varepsilon$ and $C$ with RBF kernel function $(\sigma=0.10)$.

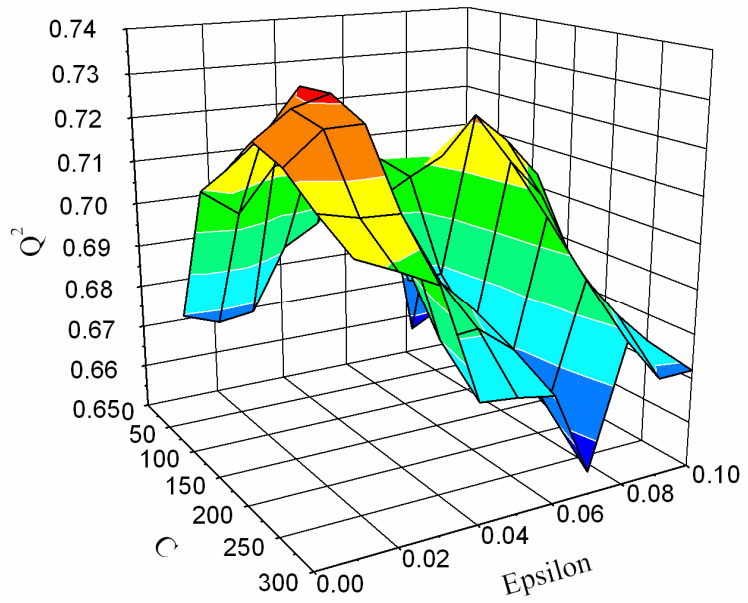

Figure 3. $Q^{2}$ versus $\varepsilon$ and $C$ with polynomial kernel function. 


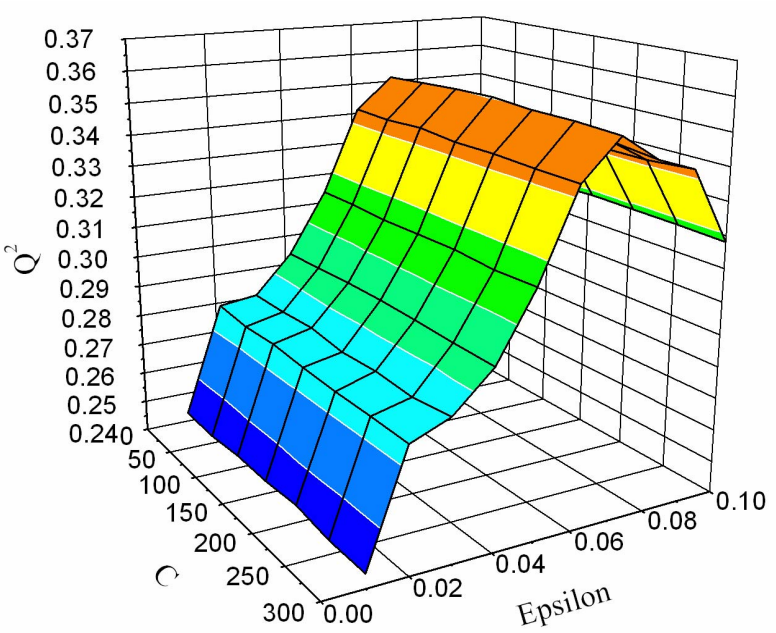

Figure 4. $Q^{2}$ versus $\varepsilon$ and $C$ with linear kernel function.

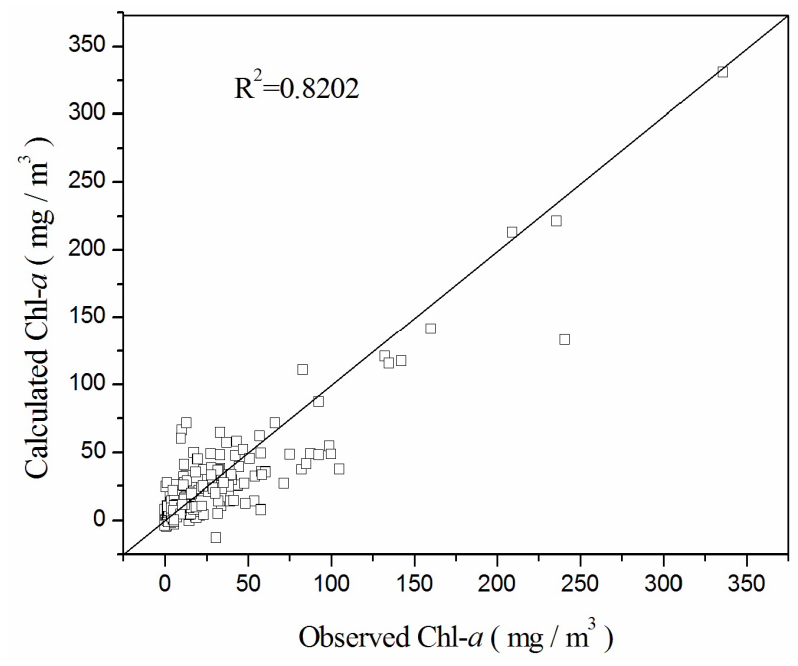

Figure 5. Observed values versus calculated values for chlorophyll-a using optimal SVR model.

where $Y_{\text {pred (Test) }}$ and $Y_{\text {(Test) }}$ represent the predicted and observed chlorophyll- $a$ values of the test set, respectively. $\bar{Y}_{\text {training }}$ is the mean chlorophyll- $a$ value of the training set.

The $R_{\text {pred }}^{2}$ values of MLR, BPANN and SVR models were $0.4127,0.7644$ and 0.7842 respectively. Figure 6 shows the predicted values of optimal SVR model versus observed values for chlorophyll- $a$. Based on the above results. The SVR method has been shown to perform well for regression and be a useful and powerful technique to construct the chlorophyll- $a$ model during spring algal bloom.

\section{Conclusion}

The support vector regression model of chlorophyll- $a$ during spring algal bloom in Xiangxi Bay of Three

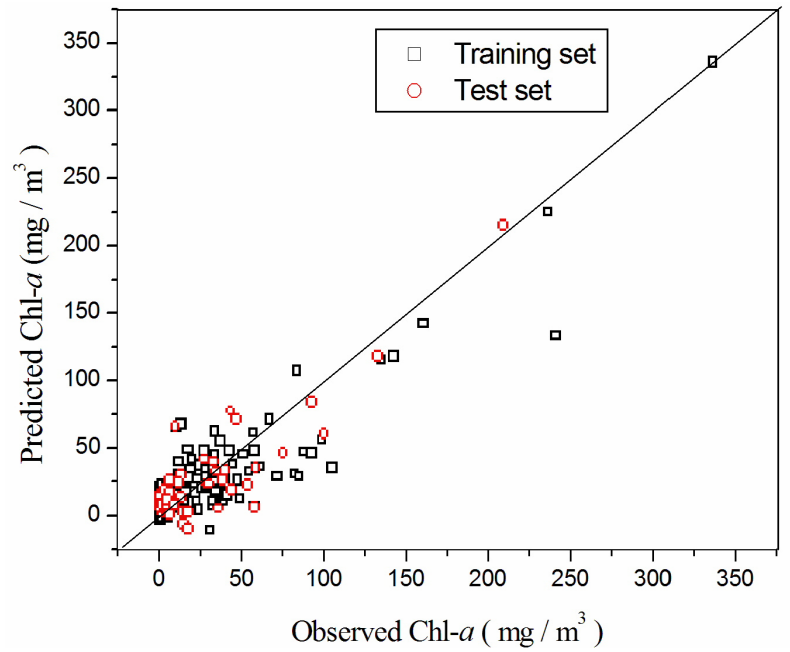

Figure 6. Observed values versus predicted values for chlorophyll-a using optimal SVR model.

Gorges Reservoir was established. Using stepwise MLR method, the important environmental variables $(\mathrm{DO}, \mathrm{pH}$, Turb, $\mathrm{PO}_{4}, \mathrm{NH}_{4}, \mathrm{NO}_{3}$ and $\mathrm{SiO}_{4}$ ) were selected. The parameters in SVR such as the type of kernel function, the regularization parameter $C$ and $\varepsilon$-insensitive loss function were optimized by leave one out cross validation. $R^{2}$ and $Q^{2}$ of the optimal SVR model are 0.8202 and 0.7301, respectively. Compared with MLR and BPANN models, the SVR model has been shown to perform well for regression with the $R_{\text {pred }}^{2}$ value of 0.7842 for the test set.

\section{Acknowledgements}

This work was funded by National Natural Science Foundation of China (No. 50679038, 51009080), National Science and Technology Support Program of China (No. 2008BAB29B09), National Water Special Project of China (2008ZX07104-004) and Hubei Province Ministry of Environmental Protection, China (No. 2008HB08). We thank Daobin Ji, Zhengjian Yang, Zhongqiang Yi, Jun $\mathrm{Ma}$, Yanmei Su, Xia Yang and Qiaoli Cao for their assistance in the field and lab.

\section{REFERENCES}

[1] S. R. Carpenter, D. Ludwig and W. A. Brock, "Management of Eutrophication for Lakes Subject to Potentially Irreversible Change," Ecological Applications, Vol. 9, 1999, pp. 751-771.

doi:10.1890/1051-0761(1999)009[0751:MOEFLS]2.0.C $\underline{\mathrm{O} ; 2}$

[2] D. W. Schindler, "Recent Advances in the Understanding and Management of Eutrophication," Limnology and Oceanography, Vol. 51, 2006, pp. 356-363. doi:10.4319/10.2006.51.1_part_2.0356 
[3] I. Kagalou, E. Papastergiadou and I. Leonardos, "Long Term Changes in the Eutrophication Process in a Shallow Mediterranean Lake Ecosystem of W. Greece: Response after the Reduction of External Load," Journal of Environmental Management, Vol. 87, No. 3, 2008, pp. 497506. doi:10.1016/j.jenvman.2007.01.039

[4] H. B. Glasgow Jr. and J. M. Burkholder, "Water Quality Trends and Management Implications from a Five-Year Study of a Eutrophic Estuary," Ecological Applications, Vol. 10, 2000, pp. 1024-1046.

doi:10.1890/1051-0761(2000)010[1024:WQTAMI]2.0.C $\underline{\mathrm{O} ; 2}$

[5] P. J. Dillon and F. H. Rigler, "The Phosphorus-Chlorophyll Relationship in Lakes," Limnology and Oceanography, Vol. 19, No. 5, 1974, pp. 767-773.

doi:10.4319/lo.1974.19.5.0767

[6] K. An and S. S. Park, "Indirect Influence of the Summer Monsoon on Chlorophyll-Total Phosphorus Models in Reservoirs: A Case Study," Ecological Modelling, Vol. 152, No. 2-3, 2002, pp. 191-203. doi:10.1016/S0304-3800(02)00020-0

[7] G. Phillips, O. P. Pietilainen, L. Carvalho, A. Solimini, A. L. Solheim and A. Cardoso, "Chlorophyll-Nutrient Relationships of Different Lake Types Using a Large European Dataset," Aquatic Ecology, Vol. 42, No. 2, 2008, pp. 213-226. doi:10.1007/s10452-008-9180-0

[8] L. Hakanson, J. M. Malmaeus, U. Bodemer and V. Gerhardt, "Coefficients of Variation for Chlorophyll, Green Algae, Diatoms, Cryptophytes And Blue-Greens in Rivers as a Basis For Predictive Modelling and Aquatic Management," Ecological Modelling, Vol. 169, No. 1, 2003, pp. 179-196. doi:10.1016/S0304-3800(03)00269-2

[9] K. K. Balachandran, K. V. Jayalakshmy, C. M. Laluraj, M. Nair, T. Joseph and P. Sheeba, "Step-Up Multiple Regression Model to Compute Chlorophyll $a$ in the Coastal Waters off Cochin, Southwest Coast of India," Environmental Monitoring and Assessment, Vol. 139, No. 1-3, 2008, pp. 217-226. doi:10.1007/s10661-007-9829-5

[10] N. K. Sharma, D. Mohan and A. K. Rai, "Predicting Phytoplankton Growth and Dynamics in Relation to Physico-Chemical Characteristics of Water Body," Water Air \& Soil Pollution, Vol. 202, No. 1-4, 2009, pp. 325-333. doi:10.1007/s11270-009-9979-x

[11] K. H. Cho, J.-H. Kang, S. J. Ki, Y. Park, S. M. Cha and J. H. Kim, "Determination of the Optimal Parameters in Regression Models for the Prediction of Chlorophyll-a: A Case Study of the Yeongsan Reservoir, Korea," Science of the Total Environment, Vol. 407, No. 8, 2009, pp. 25362545. doi:10.1016/i.scitotenv.2009.01.017

[12] Y. Liu, H. Guo and P. Yang, "Exploring the Influence of Lake Water Chemistry on Chlorophyll- $a$ : A Multivariate Statistical Model Analysis," Ecological Modelling, Vol. 221, No. 4, 2010, pp. 681-688. doi:10.1016/j.ecolmodel.2009.03.010
[13] M. Xu, G. M. Zeng, X. Y. Xu and G. H. Huang, "Application of Bayesian Regularized BP Neural Network Model for Analysis of Aquatic Ecological Data-A Case Study of Chlorophyll a Prediction in Nanzui Water Area of Dongting Lake," Journal of Environmental Science, Vol. 17, No. 6, 2005, pp. 946-952.

[14] K.-S. Jeong, D.-K. Kim and G.-J. Joo, "River Phytoplankton Prediction Model by Artificial Neural Network: Model Performance and Selection of Input Variables to Predict Time-Series Phytoplankton Proliferations in a Regulated River System," Ecological Informatics, Vol. 1, No. 3, 2006, pp. 235-245. doi:10.1016/j.ecoinf.2006.04.001

[15] V. Vapnik, "Statistical Learning Theory," Wiley, New York, 1998.

[16] V. Vapnik, "An Overview of Statistical Learning Theory," IEEE Transactions on Neural Networks, Vol. 10, No. 5, 1999, pp. 988-999. doi:10.1109/72.788640

[17] U. Thissen, R. van Brakel, A. P. de Weijer, W. J. Melssen and L. M. C. Buydens, "Using Support Vector Machines for Time Series Prediction," Chemometrics and Intelligent Laboratory Systems, Vol. 69, No. 1-2, 2003, pp. 3549. doi:10.1016/S0169-7439(03)00111-4

[18] J. G. Wu, J. H. Huang, X. G. Han, Z. Q. Xie and X. M. Gao, "Three-Gorge Dam-Experiment in Habitat Fragmentation?" Science, Vol. 300, No. 5623, 2003, pp. 12391240. doi:10.1126/science. 1083312

[19] L. Ye, D. F. Li, T. Tang, X. D. Qu and Q. H. Cai, "Spatial Distribution of Water Quality in Xiangxi River, China," China Journal of Applied Ecology, Vol. 14, No. 11, 2003, pp. 1959-1962.

[20] T. Tang, D. F. Li, W. B. Pan, X. D. Qu and Q. H. Cai, "River Continuum Characteristics of Xiangxi River," China Journal of Applied Ecology, Vol. 15, No. 1, 2004, pp. 141-144.

[21] H. Y. Wang, "Effects of the Three Gorges Reservoir on the Water Environment of the Xiangxi River with the Proposal of Countermeasures," Resource and Environment of Yangtze Basin, Vol. 14, No. 2, 2005, pp. 233-237.

[22] X. C. Jin and Q. Y. Tu, "Criterion of Eutrophication Survey on Lakes," 2nd Edition, Environmental Science Press, Beijing, 1990.

[23] A. J. Lewitus, E. T. Koepfler and J. T. Morris, "Seasonal Variation in the Regulation of Phytoplankton by Nitrogen and Grazing in a Salt Marsh Estuary," Limnology and Oceanography, Vol. 43, No. 4, 1998, pp. 636-646. doi:10.4319/10.1998.43.4.0636

[24] S. R. Gunn, "Support Vector Machines for Classification and Regression," Technical Report, Image Speech and Intelligent Systems Research Group, University of Southampton, Southampton, 1997. http://www.isis.ecs.soton.ac.uk/isystems/kernel/ 